\title{
A CONCEPTUAL FRAMEWORK FOR UNDERSTANDING PRE-ENTRY FACTORS INFLUENCING FIRST-YEAR UNIVERSITY EXPERIENCE
}

\author{
S. Pather* \\ e-mail: pathersu@cput.ac.za \\ R. Chetty* \\ e-mail: chettyr@cput.ac.za \\ *Education Department \\ Cape Peninsula University of Technology \\ Rondebosch, Cape Town, \\ South Africa
}

\section{ABSTRACT}

Student cohorts entering universities in South Africa have become more diverse; making the first-year experience more complex to understand. In order to address these challenges, a conceptual framework that accounts for the situated circumstances of the diverse students entering higher education is explored. The conceptual framework integrates key concepts from Bourdieu's $(1984 ; 1990)$ conceptual tools and Tinto's $(1975 ; 1993)$ student integration model. The framework facilitates in-depth understanding of pre-entry factors influencing first-year experience. To test the efficacy of the conceptual model, an analysis of one student's negotiations through her first-year university experience is reported. This article highlights the utility of this framework, identifying the manner in which pre-entry factors from the participant's situated context assisted in explaining how habitus shaped her first-year experience and academic performance. The themes identified: determination, motivation and self-resilience, helped understand why this participant made decisions that influenced her social and academic integration at university. Study outcomes suggest some initial insights and a starting point to influence actions that might improve university transition and integration of students from relatively disadvantaged backgrounds.

Keywords: first-year experience, habitus, social integration, academic integration, cultural capital

\section{INTRODUCTION}

Since the advent of democracy, South African universities have become more racially and culturally diverse. In accordance with the diversity of a mixed student population, students' 
needs and expectations have become increasingly heterogeneous (Nelson et al. 2011). The need for Higher Education Institutions (HEIs) to appreciate, and adjust to, such diversity is particularly urgent amongst first-year students, considering that many South Africans entering university do so from positions of extreme inequality, in terms of schooling, race, class, and socio-economic resources. McInnis (2001), together with Nelson et al. (2011), demonstrate that the significance of religious, racial, economic and cultural diversity on students' first-year experience has been underestimated and that further research is essential to determine how diversity can add value to the first-year experience of all students. This is in accordance with the view that the first-year experience has been highlighted in recent research as a critical factor with regard to persistence, academic performance, retention, assessment and success (Harvey, Drew and Smith 2006). This study takes into consideration the significance of diversity in understanding first-year experience and thus employs concepts from two sociological models, Tinto's integration model (1975; 1993) and Bourdieu’s theoretical tools of capital, habitus and field (1984; 1990), to examine pre-entry factors influencing first-year experience.

Over the past two decades, a dominant influence in theoretical literature on student retention and first-year experience has been the contribution made by Tinto (see for example, Tinto 1975; 1993). He developed a longitudinal student integration model explaining the process of student departure (drop out) from higher education. Tinto's retention model asserts that, for a first-year student to be successfully integrated into university life, integration must take place in both the social and academic domains (Tinto 1975). The first-year student's level of integration can be influenced by internal and external factors. Tinto considers preuniversity characteristics such as family background, skills, abilities and prior schooling experiences as factors influencing the students' initial goal and university commitments which determine the level of academic and social integration. Such assimilation, in turn, often decides the success or failure of students at first-year. However, although Tinto's model mentions students' background characteristics as pre-entry factors, these are considered only in passing and with very little rigour. Many of the studies applying Tinto's model consider the students' pre-entry characteristics such as socio-economic status, academic experience and demographics, as control variables rather than considering each of these key factors being 'investigated as variables whose effects are important to understand' (Walpole 2007, 8). Additionally, Reay $(2012,2)$ picks up on this tendency to ignore these factors and warns that research and literature on higher education student experience and retention have largely overlooked the influence of students' background characteristics.

The focus of any new model for analysis, then, must be to consider the significance of 
pre-entry factors such as religious, racial, economic and cultural diversity, in influencing the way students negotiate their first-year experiences. In order to fully explore pre-entry factors, Tinto's integration concepts, which have been widely used but critiqued, together with Bourdieu's (1984; 1990) theoretical tools provided a suitable and expanded conceptual framework for exploring the interactions and influences between students and their particular contexts. The conceptual model discussed and tested in this article acknowledges that individuals have multi-layered realities. For example, students have multiple roles and responsibilities; as student, as parent/carer, as employee, as family member, as well as possible loyalties to social or religious groups and communities.

\section{TOWARDS A CONCEPTUAL MODEL}

The justification for employing concepts from Bourdieu's and Tinto's theories in the conceptual framework model was to address a gap in the literature on first-year experience. The authors sought to fill this gap by contributing empirical research to the first-year experience field by means of examining and understanding what, how and why certain preentry academic and non-academic factors influence students' first-year experience and academic performance. This article reports on the first stage in developing that aim. This involves a detailed case study of one student, who we call Joyce, to test the newly expanded model and provide a narrative showing how she structured her choice of coming to university and in turn how this influenced the structuring of her circumstances to help shape a better future for herself.

The understanding of pre-entry factors, particularly racial, socio-economic and cultural resources influencing first-year experience, is pivotal to accommodating the diversity of the higher education student body. Many studies on first-year experience that employ Tinto's concept of social and academic integration focused on student retention and rarely discuss factors influencing integration in detail (Wilcox, Win and Fyvie-Gauld 2005). These studies also lack analysis on how and why such social and academic integration takes place. Harvey, Drew and Smith (2006) concur and acknowledge that, although there has been a large amount of data collected on the students' first-year experiences at the institutional level, relatively few studies have explored and reported on students' personal experiences in their first year of study. This is particularly true for South African contexts.

Research so far has focused mainly on factors within the university environment for example, academic performance, student learning, academic support, student retention and drop out. However, Lane and Taber (2012), recommend observing the roles played by social class, capital and habitus to students' educational experiences and academic success. It is 
therefore apparent that factors external to the university environment cannot be ignored when investigating first-year experiences. The authors of this study recognised this area as a gap in the literature and the need for more studies done in South Africa that investigate students' first-year university experience by considering the influences of factors external to the university environment, such as students' habitus and different forms of capital. With the changing landscape of student diversity in South African universities, we believe there is a growing urgency for a critical exploration and understanding of pre-entry factors influencing students' higher education experiences through the voice of first-year students. This will provide first-year curriculum planners and student support services with initial insights which could be a consideration when planning for their incoming first-year cohort. The conceptual framework highlights diversity as the key principle that universities should consider, i.e. students from diverse backgrounds bring with them different attributes to the academe, especially disadvantaged students who not only have financial challenges, but also are highly motivated together with a strong level of perseverance. According to a study done by van Zyl, Gravett and De Bruin (2012, 1108), a more accurate profile of newly entering students will allow the implementation of more thoughtful early intervention strategies.

Integrating the concepts from the two theorists, Tinto and Bourdieu, into one expanded conceptual framework provided a lens to fully capture in-depth understanding of the complexities of pre-entry factors. While Tinto's model of integration provided the scope to be descriptive and provide explanations at a practical level, Bourdieu's concepts of capital, habitus and field were used as both conceptual and analytical tools. Finally, the conceptual model heightened our gaze providing a more detailed explanation of how the students' environment in which they were raised and their social, academic and cultural existence, shapes their attitudes, interpretations of their first-year experiences and their capacity to engage with academic and social integration in the first year of study (Bourdieu and Passeron 1977).

The following section discusses how the new model came about with some discussion and critique of the two theories involved in its construction.

\section{USING TINTO AND BOURDIEU'S CONCEPTS TO DEVELOP THE CONCEPTUAL MODEL}

\section{Tinto's integration model}

Tinto’s student integration model (Tinto 1975; 1993) provides a conceptual framework used by many researchers to develop, collect and analyse empirical evidence in studies focussing 
on issues such as student persistence, attrition, academic performance, success, and engagement (Abramson and Jones 2003; Horstmanshof and Zimitat 2007; Kuh et al. 2007). Tinto's model has also been applied in different settings ranging from multiple institutions to individual programmes and subjects. Tinto's model has largely contributed to understanding of student drop out and persistence. Tinto's model has also been useful in predicting at-risk students (Pascarella and Terenzini 1978).

Tinto's (1975) theory of student departure suggests four distinct features in the process to student departure:

- $\quad$ Student entry characteristics.

- Initial commitment to goal and institution.

- Social and academic integration.

- Subsequent commitment to goal and institution.

Tinto states that students enter university with various individual characteristics, such as: background (family; parental educational level; socio-economic status); individual attributes (age, sex, race, ability) and prior academic experience (schooling experience, grades), all play a role in student departure, directly influencing decisions to either stay on or drop out of university. Tinto (1975) hypothesises that students' entry characteristics also directly influence their initial commitment to the institution and their goals to graduate. Tinto's model suggests that the students' initial commitment to an institution and goals to graduate consecutively influence the student's degree of integration into the social and academic domains of the institution.

Academic integration, referring to students' formal interactions with lecturers, students and support staff, can be defined under two dimensions: structural and normative integration. According to Tinto $(1975,104)$, structural integration involves the students meeting the explicit standards of the university required for academic achievement, while normative integration relates to an individual's identification with the normative structure of the academic system. Tinto $(1975,106)$ also adds that normative integration takes the form of congruency between the individual's intellectual development and the intellectual environment of the university. Social integration refers to students' non-formal networks and associations with peers, academic staff and extra-curricular activities. Tinto $(1975,107)$ suggests that social integration concerns the degree of congruency between the individual student and the social system of the university.

In Tinto’s model, the formation of students' subsequent commitments to the university 
and their goals to succeed are directly affected by their level of social and academic integration. Tinto $(1975,110)$ posits that the greater the level of academic integration, the greater the level of subsequent commitment to the students' academic goals. Similarly, Tinto adds that the greater the level of social integration, the greater the level of the students' subsequent commitments to the university. Tinto adds that students' initial commitment also shape their subsequent university and goal commitments which will influence persistence to study. In this regard, Tinto's model asserts that students who engage in formal and informal academic and social integration are less likely to leave their institutions. Harvey, Drew and Smith (2006) add that the integrative and positive experiences at university reformulate the students' goals and commitments, thus reinforcing longer term commitment and persistence.

Tinto's (1993) theory of student departure highlights academic and social integration as two constructs representing the process of student adjustment to their new university environment. He adds that these two clusters of behaviour influence students' overall performance and affective responses to the university experience. Tinto (1975; 1993) suggests that compensatory mechanisms can be applied with regard to academic and social integration. For example, Tinto suggests that a high level of academic integration can compensate for a lower level of social integration and vice versa; however he does caution that an excessive level of social integration can impact academic performance. This study examines Tinto’s two constructs, social and academic integration, to understand how and why certain pre-entry factors influence students' overall integration in the university environment.

\section{Critique of Tinto's model}

Tinto's (1975) model has been said to focus heavily on traditional, white, young American first-year students in private residential institutions. Consequently, this has led to his model being criticised for being; too homogeneous (Brunsden et al. 2000); its inability to explain racial minority student retention (Stage and Anaya 1996; Rendón et al. 2000); studying attrition of only older students (Bean and Metzner 1985) and neglecting the 'widened community' of students that resulted from increased access (Rhodes and Neville 2004, 179).

A further critique relates to Tinto's use of academic and social integration, central to his model on student integration. Tierney (1992) distinguished that these constructs were too broad and do not address specific examples that could be related to students from nontraditional entry routes into higher education. Melguizo (2011, 403) adds that Tinto does not provide explicit definitions or give clarity to his concepts of academic and social integration or on measuring such constructs. This has resulted in researchers defining and measuring 
these constructs to fit their own purposes.

An additional and significant critique of Tinto's model concerns cultural limitation. Tierney (1992) critiqued Tinto’s model for misrepresenting the cultural aspects of transition which placed great emphasis on student drop-out as an individual matter. Tierney suggested that Tinto’s misinterpretation of Van Gennep’s 'rite of passage' (as cited in Tierney 1992, 608), which makes reference to his transition ritual that moves an individual from one social status to another in a three stage process of separation, transition and integration, holds potentially harmful consequences for racial and ethnic minority students as it encourages minority students to separate from their cultural traditions and supportive relationships.

Nonetheless, the work of Tinto has been fundamental in establishing the role of the institution in fostering an environment for student integration and remains relevant in this regard. Tinto acknowledges the limitations of his model and recognises a range of other interpretations that are sociological, psychological and economic in nature that can be used to explain student retention (Tinto 2007). In this regard, this study relied upond Bourdieu's (1990) sociological theory integrated with Tinto’s concepts to obtain a deeper understanding of the complexities of pre-entry factors influencing the students' first-year experience and integration into the university environment.

\section{Bourdieu's theoretical tools}

Bourdieu's theoretical tools $(1984 ;$ 1990) have been used by a number of researchers to explore differential higher education experiences by gender, race and class of the varying student population, which are namely: minority students (Ovink and Veazey 2010); black students (Jones 2001); first-generation/non-traditional students (Watson et al. 2009); lowincome/working-class students (Devas 2011) and by gender (Dumais 2002). Many of the studies focus specifically on Bourdieu's concept of habitus to explain, interpret and understand institutional habitus, individual and collective student habitus and the habitus of academic staff (Kloot 2009; Reay 2004). Cultural capital was also regarded as a tool to explore its influence on student behaviour and experiences (Ball et al. 2002).

Bourdieu's theoretical tools, also termed 'thinking tools' (Bourdieu and Wacquant 1989, 50), are used to explain how the environment in which individuals are raised and their conditions of cultural and material existence, shape their attitudes, means of interpreting the world and their capacity to engage with higher education discourse (Bourdieu and Passeron 1977). These theoretical tools are predominantly applied to understand the social world which Maton (2008) explains is not simply the result of one's habitus but rather of relations between habitus and one's current circumstances. For Bourdieu, habitus, capital and field are 
unavoidably interrelated, both conceptually and empirically (Bourdieu and Wacquant 1992, 96-97). To understand and interpret habitus without reference to capital and field is to extract habitus from the very context in which it operates and derives its meaning (Maton 2008, 18).

Bourdieu describes field as a socially structured space in which individuals play out their engagements with each other. Warde $(2004,12)$ however, regards a field as a relatively autonomous structured space, which has been socially instituted and has a definable but contingent history of development. Bourdieu $(1984,224)$ frequently employs the analogy of a game when conveying the sense of activity within a field adding that, it is within a specific field that capital and habitus come into play. Berger (2000, 99) asserts each field has its specific logic dictating different amounts of, and types of, capital that can be used for competitive advantage. In order to 'play the game' in the field, Bourdieu states that individuals need to have 'some existing stock, namely, capital that is relevant to the new field' $(1984,446)$. Bourdieu defines capital as 'any resource that holds symbolic value within a field and therefore acts as a currency that actors take with them to the field' $(1984,446-7)$. Bourdieu (1986, 245) identifies three types of capital: economic, cultural and social. Economic capital is regarded as 'immediately and directly convertible into money', while cultural capital refers mainly to the products of education, whether these are visible in individuals (accent, vocabulary, behaviour), connected to objects like qualifications, or connected to institutions such as schools and universities (Bourdieu 1986, 246). Social capital is an individual's social connections or networks of lasting relations that have been established and continue to expand (Bourdieu 1986, 246).

Bourdieu's concept of habitus offers an insightful way of understanding social interactions within a field and therefore can be described as a set of values, practices and norms which people assimilate as part of who they are and how they operate. It represents how individuals make use of their past and present experiences to address a current situation. Bourdieu explains habitus as, 'systems of lasting, transposable dispositions which, integrating past experiences, functions at every moment as a matrix of perceptions, appreciations, and actions' (1971, 83). Formally, he defines habitus as a property of actors (whether individuals, groups or institutions) that comprises a, 'structured and structuring structure’ (Bourdieu 1994, 170). It is 'structured' by one's past and present circumstances, such as family upbringing and educational experiences. One's habitus helps to shape one's present and future practices. It is a 'structure' in that it is systematically ordered rather than random or haphazard. This 'structure' comprises a system of dispositions which generate 'perceptions, appreciations and practices’ (Bourdieu 1990, 53). 


\section{Critique of Bourdieu}

Although Bourdieu's theoretical tools have been applied and reviewed by many researchers, they have been subject to some criticism. Kingston (2001) and Sullivan (2002) criticised Bourdieu for the vagueness of his concepts and lack of a more explicit description, for example, not being precise about exactly which of the resources associated with high-class homes contribute to cultural capital and how these resources are converted into educational credentials. But, these researchers acknowledge that the concept of cultural capital, although not constructed concisely by Bourdieu, is substantive enough to be potentially useful to empirical researchers. With regard to Bourdieu's concept of habitus, Sullivan (2002) argues that this concept is theoretically incoherent and has no clear use in being operationalised or interpreted for empirical work. However, James (2011), however, elaborates that Bourdieu's tools can be helpful to researchers to be more specific about their unit of analysis and will assist in transforming the ways in which we see the social world.

An alternative to choosing either Tinto's model of student integration or Bourdieu's conceptual tools is to integrate both theories to form a conceptual framework providing a more holistic approach to understanding, exploring and interpreting first-year students' university experience and academic performance. The graphical illustration of the integrated model (Figure 1) identifies four sets of variables providing and accounting for a more inclusive range of influences on students' first-year experience and academic performance: students’ habitus; students’ capital; students’ social and academic integration and individual students’ first-year experience.

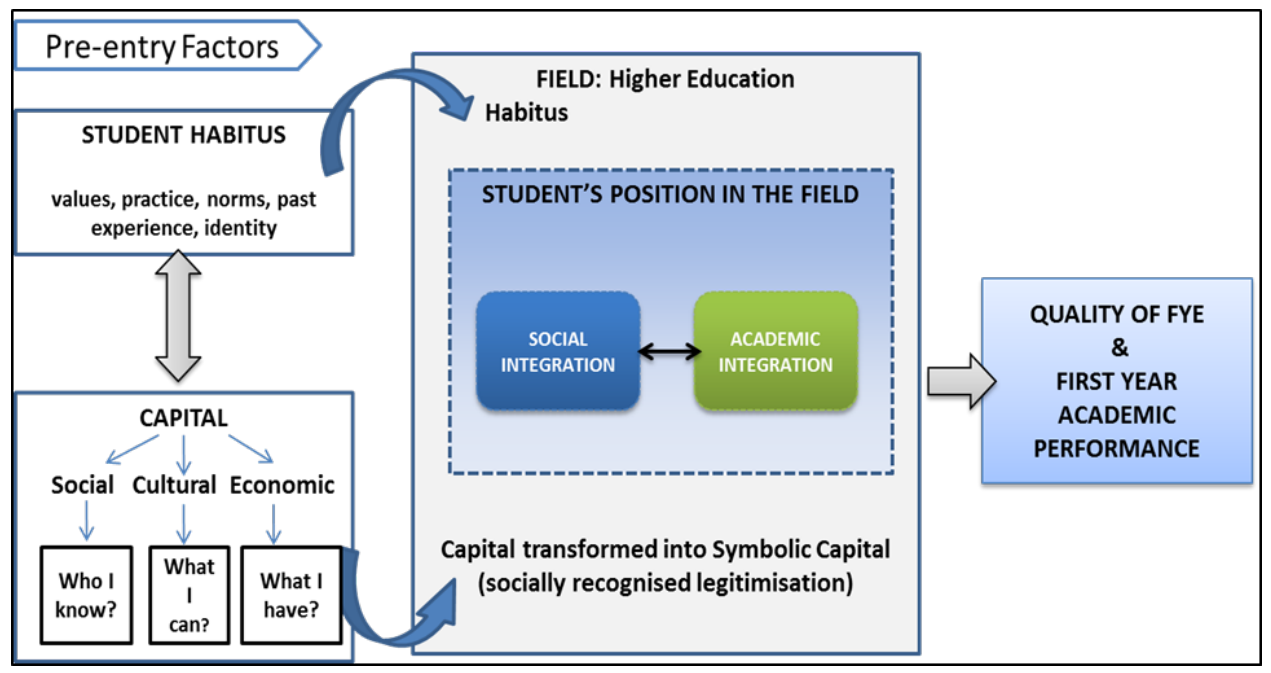

Figure 1: An integrated model to understand First-year Experience (FYE) (Source: Pather 2015, 56) 
The new expanded and integrated conceptual model takes into account that students come to university with a range of academic and non-academic (social and personal) background characteristics and experiences which, in Figure 1, are referred to collectively as the student's habitus and capital. Students make use of varying levels of their different forms of capital and habitus to negotiate their first-year university experiences. Different experiences and characteristics from their capital and habitus may positively and/or negatively influence their integration into higher education. These dispositions both prepare and dispose the students, in varying degrees, to integrate socially and academically in their new field, the higher education context. The interaction between the student and the institutional context can impact students' sense of belonging, and hence the quality of their first-year experiences. Tinto informs that when students sense incongruence between the institution and/or their academic community, and how they perceive themselves, this could result in alienation and increased likelihood of drop-out. Tinto refers to this isolation as the, 'absence of sufficient interactions whereby integration can be achieved' (1987, 53). Lack of congruency and isolation can negatively impact upon students' overall university experience and academic performance.

Taking into account the student's capital and habitus ensures better understanding of their academic and social integration which is, in turn, necessary for understanding the student's sense of belonging or fit. A student's sense of belonging is linked to a sense of congruence influenced by the environment in which the student was raised, thereby shaping their attitudes and interpretations of new university experiences and affecting their abilities to integrate. These interactive factors could also determine whether the student decides to persist into second year or drop out of university.

\section{APPLICATION OF THE CONCEPTUAL MODEL TO UNDERSTAND THE EXPERIENCE OF ONE FIRST-YEAR STUDENT (JOYCE)}

In this section we highlight the practicality and applicability of the expanded conceptual framework to understand how students' habitus and different forms of social, economic cultural capital influence social and academic integration. Gaining this knowledge should allow first-year lecturers, administrators and curriculum planers to:

- $\quad$ Better understand who are the first-year students entering higher education.

- Gain familiarity with specific pre-entry factors that influence the students' first-year experiences. 
- Ascertain how these factors influence the students' first-year academic and social integration and academic performance.

- $\quad$ Propose strategies to enhance the quality of students' first-year experience in higher education.

In this section we report on one participant's voice of her experiences of being a first-year university student. We purposefully selected Joyce (pseudonym) to test out the expanded, integrated conceptual model as Joyce proved a suitable candidate who had a diverse range of characteristics and experiences that could be used to test the model. Joyce is an African ${ }^{1}$ female from a rural settlement and lived with her grandmother before moving to Cape Town to live with her aunt. Joyce received a scholarship to attend a private school in Cape Town. She was eager to share her story, expectations and experiences with us. In order to obtain information that captures Joyce's habitus and use of capital resources available to her and to explore influences on the way this student navigated her first year of university, we opted to focus on particular themes when interviewing Joyce. The aim in doing this was to gauge to what extent the new model and the related analysis might be applicable to a wider range of cases. Joyce was asked to talk about her family life, schooling experience, her expectations of university and her social and academic experiences on campus. Guiding the analysis of the data emerging from her interview was our conceptual framework (Figure 1). We analysed outcomes of her interview within four sets of variables based on our conceptual framework: students' habitus signified family background, prior schooling experience and reported confidence and entitlement; students' capital denoted social capital, family support, friends and other networks, cultural capital, skills, knowledge and behaviour, economic capital, financial support; and the last two variables were the student's extent of social and academic integration. The key themes that emerged from our analysis concerned Joyce's motivation, determination and self-resilience and each of these is underscored by the discussion that follows. These themes are not isolated entities nor are they treated separately in the discussion section that follows; thus avoiding the risk of reducing the value of Joyce's overall story emerging from the interview analysis.

\section{DISCUSSION - JOYCE'S STORY}

In order to discuss how habitus and capital influenced Joyce's social and academic integration at university the narrative of her life, as it affected university experiences, will be summarised according to the conceptual model proposed. In analysing the transcript of her 
interview, it was clear that the key emerging themes, motivation, determination and selfresilience, resulting from her habitus, influenced Joyce's social and academic integration and her sense of belonging. According to Tinto, adjusting to first-year university and the required academic performance, occurs when a student successfully integrates both academically and socially. In addition to integration being affected by pre-entry characteristics and goal commitments, interactions with peers and faculty, out-of-classroom factors can play a part (Jensen 2011). For Bourdieu (1994), integration and a sense of belonging is informed by one's habitus and past experiences. Bourdieu explains that habitus operates in two key ways: it is structured by one's circumstances and it structures, in that it shapes one's present and future practices (1994, 70). Paulsen and St John (2002) warn that when studying diverse student groups it is imperative that the student's situated circumstances be taken into account. These authors elaborate on situated contexts to encompass the students' prior educational and background experiences that are shaped by their values, limited resources and capital. In the narrative and discussion that follow, it can be seen that, in these terms, Joyce's past experiences structured her choice of coming to university and in turn influenced the structuring of her circumstances to help shape a better future for herself.

\section{Joyce's upbringing}

Joyce is a 22 year old African female from a working class family in the Eastern Cape. She had five members in her family; her parents, one sister, a twin brother and herself. Her parents separated when she was five years old and she does not have much recollection of her time with her father. She spent most of her childhood life with her grandmother and siblings as her mother had moved to Johannesburg to increase her chances of finding a good job. Joyce and her siblings attended a rural primary school in the Eastern Cape. She remembers her grandmother teaching her about her culture and acceptable behaviour:

In my culture your parents and grandparents groom you on how to treat people. My grandmother told us that we should respect our elders and she also told us how we should relate to people.

When Joyce was eleven years old her grandmother died and they moved to Johannesburg to stay with her mother. The following year Joyce's mother died and she and her siblings moved to Cape Town to live with her aunt. Joyce had to take on the responsibilities of her mother and grandmother with her siblings:

Being without a parent at a young age you have to grow up so quickly so it’s like you know ... I 
... I have to grow up. I can't just, sometimes I feel like I want to be a child, but I can't ... I have to be there for my sister and brother.

In 2005 Joyce received a scholarship to attend a private school in Cape Town. She felt it was this experience that gave her the confidence and aspiration to shape her life and engage further with education:

I went to a very good school and I was exposed to white teachers, I even had a white lady teaching me IsiXhosa. I was mainly with other races and this helped me as I don't have a problem with mixing ... Everything that we did was English first language, so yeah, that gave me an advantage because we did all sort of things in the school ... I am very confident and they groomed me very well to be the person I am today in terms of academic and socially.

In 2006 Joyce became pregnant and was forced to move out of her Aunt's house. She went to live with her boyfriend and his family. Joyce's focus was to finish high school and take care of her son. Joyce, however, was faced with many difficult circumstances. In 2007, a year before she successfully completed high school, her twin brother died and three years later her sister died. Joyce felt alone and abandoned. The only people with whom she felt a sense of belonging and regarded as family were her boyfriend and her son. In 2009 Joyce enrolled at university but dropped out soon after, she felt it was a wrong choice of study. She worked as a salesperson to support her son and herself before deciding to go back to study in 2012. She felt confident about her choice of study and regarded her maturity and desire to create a better life for herself and her son as her inspiration to succeed:

I decided I wanted to study ... I'm gonna quit work because I want to do something better for me and my son, so basically, I just said to myself, 'you know what ... next year I'm going to university', which is this year, then it was just a decision.

It was evident that Joyce's decision to go to university was not navigated by family influences. It was her own choice. Joyce had faced numerous challenges presented by her upbringing. Her 'structured' habitus from her past circumstances was 'restructured' by her educational experience at the private school. This structuring explains Joyce's decision to go to university. Maton (2008) believes that habitus is continuously adapted and restructured across different circumstances. For example, with Joyce's new experiences, her beliefs about what her culture considered to be acceptable behaviour, as taught to her by her grandmother, changed:

I think culture is a personal thing for me. I mean yeah our grandparents and our parents 
groomed us to be people that respect other people and how we relate to other people. I think it becomes a personal thing as we grow up we tend to see people in a different way ... We are exposed to different races, different cultures, how people see themselves ... You know, for me personally, because as I grew up as a teenager I had to learn things on my own.

Joyce's circumstances influenced by family habitus initially lacked the social, economic and cultural capital usually communicated and afforded by socially and economically stable families. As a result, Joyce had to adapt her habitus. Her inspiration and motivation to attend university, although partially influenced by the habitus of her working class background, was later influenced by the cultural capital transmitted from the private school she attended. In McDonough's research she found that cultural capital was not only promoted by parents but could also be transmitted through the culture of the school, school agents and peers (McDonough 1997).

The following sections interrogate how Joyce's modified habitus and cultural capital influenced her social and academic integration at university.

\section{Academic integration}

Joyce's challenging habitus and the cultural capital that accrued from her educational experiences at the private school, made her feel equipped to 'play the game' at university. Thus she felt confident, equipped and completely committed to her goal of being successful in her studies. Her level of integration with academic activities was influenced by her main focus goal; to complete her degree and obtain a job that would provide a better life for her and her son.

Joyce is the first in her family to attend university; she wishes her mother was alive to witness this event. She is determined to succeed and feels comfortable in her new environment. Her schooling experience has given her the skills to communicate confidently, especially in English which is her second language. Her cultural capital allows her to express herself; as a result talking to her lecturers and peers comes quite naturally for her:

I'm never uncomfortable because I know why I'm here. I don't have problems with speaking to the lecturers ... if I don't know something I'll ask and if I don't understand I will ask the lecturers or the peers ... like in Numeracy ... so if there's something I don't understand then I will speak to the lady and she will explain to me. I need to understand.

Joyce is driven by her level of commitment to be successful in her studies which impacts her choice of peers when it comes to working in groups on assignments and projects. She is determined to obtain the best marks and is quite specific of peers she is willing to work with 
to reach this goal:

In terms of work when I do assignments, I don't mix with my own people like the Black ... because there is always an excuse when you have to do work ... so I said, 'no, to me moving to the people I know' ... if we come to school we do the assignment and then we go home, you know. But if you have my people doing the assignment it is a problem because they will tell you that there is a problem at home, there is this, there is that. I mean I also have things that I have to do at home. I have a son and he keeps me busy all the time but I have to make time for my studies as well because that is just as important, you know what I mean.

Joyce's upbringing and past circumstances have given her the insight to understand her 'own people's' attitude to work, time management and their inclination to procrastination, however she doesn't want to submerge herself in these issues as she is firmly driven and focused on her goal to graduate. However, she is willing to help her African peers as she is aware of their disadvantaged circumstances

I look at the education that others [African students] get from the township, it's like, the standard is just not right.

Joyce tries to talk to her peers to change their attitude towards academic work:

I told them [African peers] when you come to university you come for a reason. I am here to study, not worry about other people's marks, you need to put yourself with people who know they are doing something positive and that will help you.

Joyce's self-resilience, high level of motivation and determination to succeed emerged as important themes that enabled her to achieve academic integration. She used varying levels of her capital resources, mainly her privileged school experience mitigated by her economic hardships, to navigate a successful academic experience.

\section{Social integration}

Joyce's low level of social activities and integration was, in part, due to her motivation to succeed at university. Her commitment to her son diminished her level of social integration. Joyce regards herself as a sociable person who gets along with all her peers, even though at times her peers from her own race group found her interactions with peers from other races questionable:

I don't have a problem to socialise with people. I talk to everyone and ... I don't know. I just mix with everyone. But it's like sometimes the people might, my people, the Black people, 
sometimes I feel like they have this attitude towards me because I interact with other races most of the time.

Joyce has a few people from university whom she regards as her friends. Her choice in friends was influenced by her determination to succeed academically which she has made quite clear to her peers:

You are not here to make friends, friends are a bonus ... focus on your marks, you are here for something.

Although Joyce is only 22 years old she feels she has no time to socialise. She has to balance her university work with her duties at home and her responsibilities of being a mother. However, obtaining a bursary has helped ease some of her responsibilities. The bursary pays for her studies and supports Joyce and her son. She feels grateful that she does not have to work and could focus all her time on her studies and her son, she seems to have worked out a convenient way to balance all her commitments:

I'm not really a party person, so mostly weekends I work at home, then during the week when I come from campus I will focus on my son. I have to make sure he does his homework. I have to do his laundry in between (her study times) and I have to cook in between. I must cook in the house so I just balance it out you know. If I cook during the week then weekends I know I don't cook so then I can focus on my studies.

Joyce's level of social integration seems to be purposeful. She was strategic in her choice of friends but maintained good relations with her peers in class. Her commitment to obtaining a university degree was always to the fore when making any academic or social decisions at university. As Tinto's student integration model suggests, students' levels of academic and social integration are often determined by their levels of commitment to their own goals and that of the institution. Joyce's commitment to her own academic goals influenced her level of integration. She opted to exert a higher level of integration on academic activities than social ones. As suggested by Tinto, compensatory mechanisms can be applied with regard to goal and instructional commitment. For example, Tinto suggests that a high level of academic integration can compensate for a lower level of social integration. Finally, Joyce's level of integration was influenced by intrinsic and extrinsic factors. Intrinsic influences included her focused goal commitment, her commitment to succeed at university and her high level of motivation and self-advocacy. Extrinsic influences included Joyce's determination to obtain a better life for herself and her son, to have a stable job and to achieve financial and family security. 


\section{CONCLUSION}

Many of the theories that highlight student experiences do so from different perspectives such as student retention, student attrition, academic performance, student engagement and success (Tinto 1993; Astin 1985; Bean 1990; Pascarella and Terenzini 1991; Berger and Milem 2000). Although these theories acknowledge pre-entry variables as important, they do not explicitly incorporate or emphasise the role and/or influence that these factors have on students' first-year university experiences. The conceptual framework tested and reported on in this article goes beyond the what questions to include and address the why and how questions of pre-entry factors influencing first-year experience and academic performance. Concepts from Tinto's model of student integration and Bourdieu's conceptual tools in the developed conceptual framework allowed a deeper examination of the interconnected factors that influence students' first-year experiences. We were able to understand how the identified factors impacted on one participant's level of social and academic integration. The framework developed highlights the socio-economic and cultural perspective of understanding first-year experience from the point of view of the student. The use of Joyce's narrative, her unique habitus and her use of social, economic and cultural capitals accumulated as part of her personal history, including those associated with her family, schooling and socio-economic status, shaped her motivation, determination and resilience to be committed to her educational goal. This commitment impacted her social and academic integration at the university.

The integrated approach of the conceptual framework developed a more holistic gaze on the relations between the field of HE students' first-year university experience and their dispositions and capital. The framework addresses students' tensions or congruence they experience at university, brought about by their sense of self, habitus and capital. This tension or congruency determines the quality of the student's first-year experience, academic performance and ultimately their decision to drop out or persist in higher education. Utilising the conceptual framework afforded a deeper understanding of who our students are, where they come from and how the skills they bring with them influence their university experiences.

The deeper view afforded by analysing Joyce's case allows us to foreground social interaction in the faculty extra-curricular activities and its alignment with the academic timetable. Intervention strategies have to be planned and sustained particularly throughout the crucial first year. The use of peer tutoring and mentorship programme should become part of a first year intervention strategy to encourage and build on students' social networks. Such 
intervention strategies might account for students' sense of self, habitus and capital. By pairing disadvantaged incoming students with 'help buddies' from similar backgrounds who have successfully faced and overcome social and academic difficulties when they were in their first year may encourage student persistence and improved academic performance (Naicker, Boshoff, Maritz and Fourie 2014). Electronic and social media, including Mobile Instant Messaging (MIM), have been successfully used to help incoming students from a wide range of backgrounds to successfully transition into South African universities (Bere 2013). Integrating the use of social and electronic media into wider university mentoring programmes is only just beginning in South Africa, but would warrant further development to encompass and account for some of the external, social and cultural factors affecting students that emerged from this study.

Joyce's case tested the usefulness of the framework developed. However, analysing other cases may well reveal embedded and nuanced aspects of habitus and capital that could affect motivation and academic success in different ways. The conceptual framework developed and reported on in this article must be subjected to further empirical testing before it is fully incorporated and introduced as a model to investigate pre-entry factors influencing students’ first-year university experience and academic performance.

\section{NOTE}

1. African, Coloured, Indian and White are the four population groupings used by Statistics South Africa. Blacks refer to African, Coloured and Indian population.

\section{REFERENCES}

Abramson, M. and P. Jones. 2003. Tinto's model of retention revisited: A case study from a 'new' British University. In Improving completion rates among disadvantaged students, ed. L. Thomas, M. Cooper and J. Quinn. Stoke-on-Trent, Trentham Books.

Astin, A. W. 1985. Achieving educational excellence. San Francisco: Jossey Bass.

Ball, S. J., J. Davies and D. Reay. 2002. 'Classification' and 'judgement': Social class and the 'cognitive structures' of choice of higher education. British Journal of Sociology of Education 23(1): 51-72.

Bean, J. P. 1990. Why students leave: Insights from research. In The strategic management of college enrollments, ed. D. Hossler, and J. P. Bean. Jossey-Bass: San Francisco.

Bean, J. P. and B. S. Metzner. 1985. A conceptual model of nontraditional undergraduate student attrition. Review of Educational Research 55(4): 485-540.

Bere, A. 2013. Using mobile instant messaging to leverage learner participation and transform pedagogy at a South African University of Technology. British Journal of Educational Technology 44(4): 544-561.

Berger, J. B. 2000. Optimizing capital, social reproduction, and undergraduate persistence: A sociological perspective. In Reworking the student departure puzzle: new theory and research on college student retention, ed. J. M. Braxton, 95-124. Nashville, TN: Vanderbilt University Press. 
Berger, J. B. and J. F. Milem. 2000. Organizational behavior in higher education and student outcomes. In Higher Education: Handbook of Theory and Research, ed. J. C. Smart, Vol. XV: 268-338. Agathon Press: New York.

Bourdieu, P. 1971. Systems of education and systems of thought. In Knowledge and control: New directions in the sociology of education, ed. M. F. D. Young. London, Collier-Macmillan.

Bourdieu, P. 1984. Distinction: A social critique of the judgement of taste. (R. Nice, trans.). Cambridge, MA: Harvard University Press.

Bourdieu, P. 1986. The forms of capital. In Handbook of theory and research for the sociology of education, ed. J. E. Richardson, 241-258. Wesport, CT: Greenwood Press.

Bourdieu, P. 1990. The logic of practice. Stanford, CA: Stanford University Press.

Bourdieu, P. 1994. Practical reason: On the theory of action. Cambridge/UK: Polity Press, 1998.

Bourdieu, P. and J. C. Passeron. 1977. Reproduction in education, society and culture. London, Sage.

Bourdieu, P. and L. J. D. Wacquant. 1992. An invitation to reflexive sociology, Cambridge, Polity Press.

Bourdieu, P. and L. J. D. Wacquant. 1989. Towards a reflexive sociology: A workshop with Pierre Bourdieu. Sociological Theory 7(1): 26-63.

Brunsden, V., M. Davies, M. Shevlin and M. Bracken. 2000. Why do HE students drop out? A test of Tinto's model. Journal of Further and Higher Education 24(3): 301-310.

Devas, A. 2011. Widening participation and the media student experience. Higher Education 62(6): 815-828.

Dumais, S. A. 2002. Cultural capital, gender, and school success: The role of Habitus. Sociology of Education 75(1): 44-68.

Harvey, L., S. Drew and M. Smith. 2006. The first year experience: A literature review for the Higher Education Academy. Heslingon, UK: The Higher Education Academy.

Horstmanshof, L. and C. Zimitat. 2007. Future time orientation predicts academic engagement among first year university students. British Journal of Educational Psychology 77(3): 703-718.

James, D. 2011. Beginning with Bourdieu in educational research. British Educational Research Association. http://bera-test.soapboxserver.co.uk/wp-content/uploads/2014/03/Beginning-withBourdieu-in-educational-research.pdf (accessed 20 June 2014).

Jensen, U. 2011. Factors influencing student retention in higher education. Summary of Influential factors in degree attainment and persistence to career or further education for at-risk/high educational need students. Pacific Policy Research Center.

Jones, L. 2001. Retaining African Americans in higher education: Challenging paradigms for retaining students, faculty, and administrators. Sterling, Va.: Stylus Publishing.

Kingston, P. 2001. The unfulfilled promise of cultural capital theory. Sociology of Education 74(Special Issue): 88-99.

Kloot, B. 2009. Exploring the value of Bourdieu's framework in the context of institutional change. Studies in Higher Education 34(4): 469-481.

Kuh, G. D., J. Kinzie, J. A. Buckley, B. K. Bridges and J. C. Hayek. 2007. Piecing together the student success puzzle: Research, propositions and recommendations, (No. 32, 5). ASHE Higher Education Report Series, 1-182. San Francisco: Jossey Bass.

Lane, L. and N. Taber. 2012. Experiences with cultural capital: Educational life stories of firstgeneration post-secondary students. Canadian Journal for the Study of Adult Education 24(2): $1-15$.

Maton, K. 2008. Habitus. In Pierre Bourdieu: Key concepts, ed. M. Grenfell, 46-66. London: Acumen.

McDonough, P. M. 1997. Choosing colleges: How social class and schools structure opportunity. Albany: State University of New York Press. 
McInnis, C. 2001. Researching the first year experience: Where to from here? Higher Education Research and Development 20(2): 105-114.

Melguizo, T. 2011. A review of the theories developed to describe the process of college persistence and attainment. In Higher education: Handbook of theory and research, ed. J. C. Smart and M. B. Paulsen, vol. 26: 396-424, Dordrecht, The Netherlands: Springer Science+Business Media.

Naicker, M., N. Boshoff, G. Maritz and A. Fourie. 2014. The development of a comprehensive peer buddies program in a merged tertiary institution: The University of Johannesburg. Journal of Counselling and Development in Higher Education Southern Africa 1(1): 12-29.

Nelson, K. J., J. A. Clarke, S. M. Kift and T. A. Creagh. 2011. Trends in policies, programs and practices in the Australasian first year experience literature 2000-2010. The First Year in Higher Education Research Series on Evidence-based Practice No. 1. Brisbane, Australia: Queensland University of Technology.

Ovink, S. and B. Veazey. 2010. More than 'getting us through:' A case study in cultural capital enrichment of underrepresented minority undergraduates. Research in Higher Education 52(4): 370-394.

Pascarella, E. T. and P. T. Terenzini. 1991. How college affects students: Findings and insights from twenty years of research. San Francisco: Jossey-Bass.

Pascarella, E. T. and P. T. Terenzini. 1978. Student-faculty informal relationships and freshman year educational outcomes. Journal of Educational Research 71: 183-189.

Pather, S. 2015. Pre-entry academic and non-academic factors influencing teacher education students' first-year experience and academic performance. DEd. thesis, Cape Peninsula University of Technology, Cape Town.

Paulsen, B. M. and P. E. St. John. 2002. Social class and college costs: Examining the financial nexus between college choice and persistence. The Journal of Higher Education 73(2): 189-236.

Reay, D. 2012. Researching class in higher education. British Educational Research Association. http://bera-test.soapboxserver.co.uk/wp-content/uploads/2014/03/Researching-Class-in-HigherEducation.pdf (accessed 12 June 2014).

Reay, D. 2004. It's all becoming a 'Habitus': Beyond the habitual use of Habitus. British Journal of Sociology of Education 25(4): 431-444.

Rendón, L. I., R. E. Jalomo and A. Nora. 2000. Theoretical considerations in the study of minority retention. In Reworking the student departure puzzle: New theory and research on college student retention, ed. J. M. Braxton, 127-156. Nashville, TN: Vanderbilt University Press.

Rhodes, C. P. and A. Nevill. 2004. Academic and social integration in higher education: A survey of satisfaction and dissatisfaction within a first year education studies cohort at a new university, Journal of Further and Higher Education 28(2): 179-193.

Stage, F. and G. Anya. 1996. A transformational view of college student research. In College students: The evolving nature of research, ed. F. Stage, G. Anya, J. Bean, D. Hossler and G. Kuh. Boston, Pearson Custom Publishing.

Sullivan, A. 2002. Bourdieu and education: How useful is Bourdieu's theory for researchers? The Netherlands' Journal of Social Sciences 38(2): 144-166.

Tierney, W. G. 1992. An anthropological analysis of student participation in college. Journal of Higher Education 63(6): 603-618.

Tinto, V. 1975. Dropout from higher education: A theoretical synthesis of recent research. Review of Educational Research 45(1): 89-125.

Tinto, V. 1987. Leaving college: Rethinking the causes and cures of student attrition (1st Ed.). Chicago: University of Chicago Press.

Tinto, V. 1993. Leaving college: Rethinking the causes and cures of student attrition. (2nd ed.). Chicago: University of Chicago Press.

Tinto, V. 2007. Research and practice of student retention: What's next? Journal of college student 
retention: Research, theory and practice 1: 1-19.

Van Zyl, A., S. Gravett and G. P. de Bruin, 2012. To what extent do pre-entry attributes predict first year student academic performance in the South African context? South African Journal of Higher Education 26(5): 1095-1111.

Warde, A. 2004. Practice and field: Revising Bourdieusian concepts. Centre for Research on Innovation and Competition (CRIC) Discussion Paper No. 65. Manchester, UK: The University of Manchester.

Walpole, M. 2007. Economically and educationally challenged students in higher education: Access to outcomes. ASHE Higher Education Report 33(3). San Francisco, CA: Jossey-Bass.

Watson, J., M. Nind, D. Humphris and A. Borthwick. 2009. Strange new world: applying a Bourdieuian lens to understanding early student experiences in higher education. British Journal of Sociology of Education 30(6): 665-681.

Wilcox, P., S. Winn and M. Fyvie-Gauld. 2005. 'It was nothing to do with the university, it was just the people': The role of social support in the first-year experience of higher education. Studies in Higher Education 30(6): 707-722. 